\title{
DAF IM ANDALUSISCHEN LANDESPARLAMENT
}

W fir möchten unseren Mitgliedern und Lesern nicht die Initiative von Daniel Orozco (BB Séneca, Córdoba) vorenthalten, der sich im März vergangenen Jahres an die Abgeordnete des PP M² José Garcia-Pelayo Jurado gewendet hat, damit diese eine parlamentarische Anfrage an den andalusischen Erziehungsminister Manuel Pezzi zum Thema des Deutschen als Fremdsprache im andalusischen Schulwesen richtet. Das Resultat ist die offizielle Haltung, die wir nun schwarz auf weiss haben, und auf die wir uns in unseren Aktionen stets berufen können: sobald Nachfrage an den Schulzentren besteht, wird diese von der Verwaltung befriedigt werden. Denn so lautet die einzige Antwort Pezzis auf die Frage nach den Kriterien für das Angebot einer zweiten Fremdsprache.

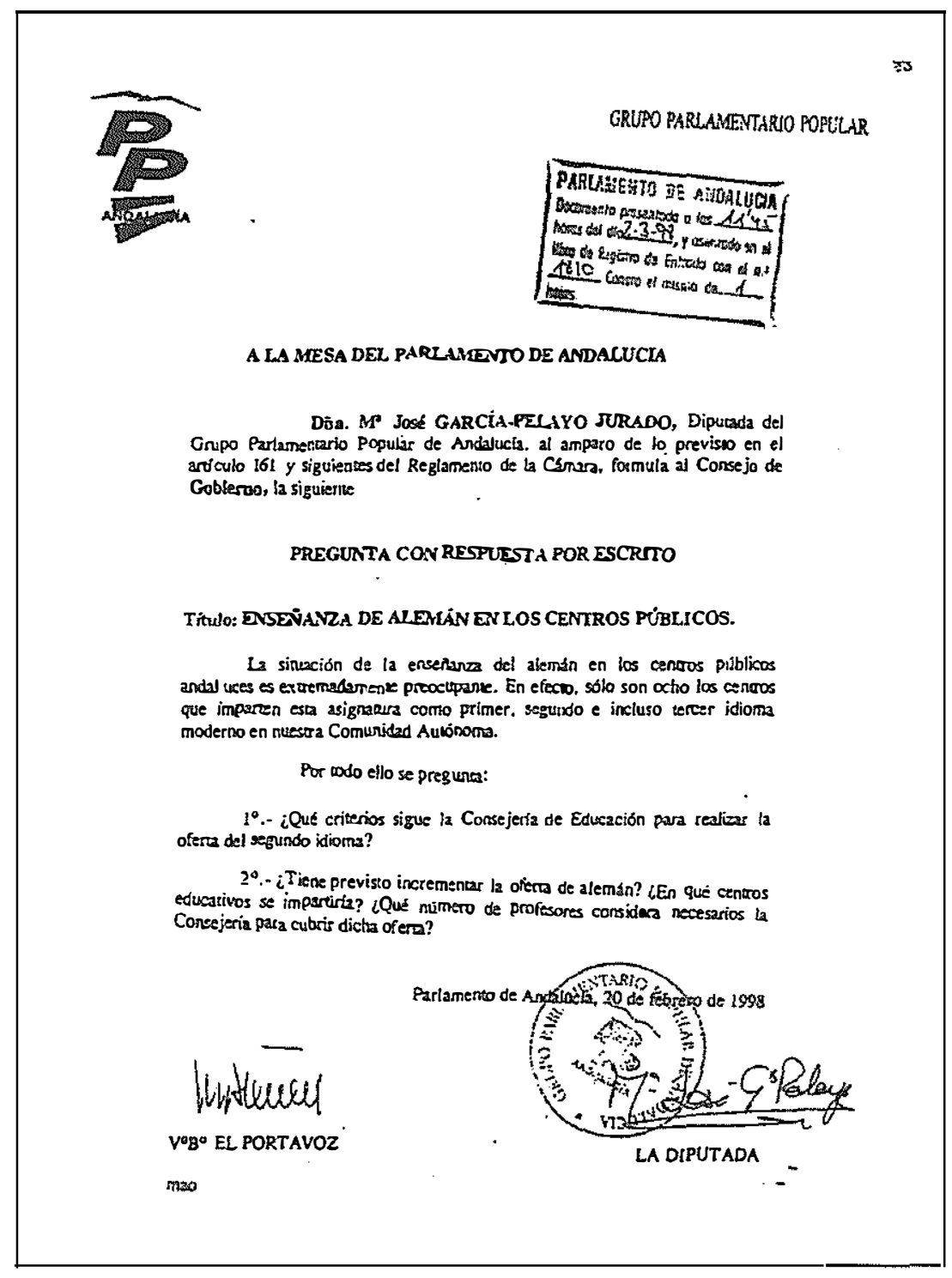


Wir reproduzieren die Antwort von Herrn Pezzi auf die parlamentarische Anfrage. (Die Besonderheiten der Wortwahl und des Satzbaus sind wohlgemerkt die des Originals):

"Respuesta a la pregunta con ruego de contestación escrita, número de expediente 5-98/PE-0001810, presentada por el Grupo Parlamentario Popular de Andalucia, relativa a: "Enseñanza de alemán en los centros públi$\cos ^{\prime \prime}$

En la actualidad, todos estamos convencidos de la importancia de las enseñanzas de los idiomas modernos para nuestro alumnado con vistas a mejorar sus perspectivas en el futuro por motivos tanto económicos y políticos como por fines culturales.

El nuevo sistema educativo en Andalucia no ha sido ajeno a esta necesidad y contempla en la LOGSE varias medidas para potenciar la enseñanza de los idiomas.

En la Educación Primaria, se adelanta el estudio de un idioma extranjero al segundo ciclo ( $3^{\circ}$ de Primera) de tal forma que todos los alumnos estudiaran un primer idioma extranjero desde los 8 años

En el primer ciclo de Secundaria Obligatoria (12-14 años), se ofertará un segundo idioma extranjero de forma opcional. La enseñanza de ese segundo idioma puede durar dos cursos si se elige en el $2^{\circ}$ ciclo de ESO o cuatro cursos académicos se lo hace en el primer ciclo y además puede prolongarse aun más si continúa sus estudios post-obligatorios. Mediante la oferta de un segundo idioma extranjero se pretende atender a la diversidad ofreciendo a los alumnos oportunidades según sus gustos y necesidades.

En nuestra Comunidad Autónoma, en el proyecto de bachillerato es obligatorio coger como optativa una segunda lengua extranjera ya que en Andalucia no existe lengua vernácula.; ese espacio se ocuparia con la enseñanza obligatoria de un segundo idioma en Bachillerato (16-18 años). También en el Bachillerato de Humanidades y Ciencias Sociales existe la posibilidad de eligir un tercer idioma extranjero. Con esta medida el alumnado ue curse tiempos ha desbancado la tradicional preferencia del francés, por lo que la lengua inglesa como primer idioma extranjero es, en la actualidad, una disciplina por la que los padres de los alumnos de educación primaria han optado y, en consecuencia, la que mayoritariamente la Administración oferta en este nivel educativo.

Esta misma tendencia y, por idénticas consideraciones, puede extrapolarse al reto de niveles educativos en los que la demanda del inglés supera a la del resto de los idiomas que podria ofertar la Administración y a ésta le sigue por orden de preferencia el francés que pasa a ser el segundo idioma más solicitado por nuestros alumnos.

No obstante esta realidad, la enseñanza del alemán se viene implantando en aquellos centros donde existe un número suficiente de alumnos que optan por esta disciplina, bien como primer, segundo y tercer idioma, existiendo en la actualidad ocho institutos de bachillerato distribuidos por la Comunidad Autónoma de Andalucia (de los cuales trs se encuentran en la Provincia de Cádiz, uno en Córdoba, dos en Granada, uno en Málaga y uno en Sevilla).

Ello no supone que el panorama descrito sea inamovible, sino que esta Consejeria está dispuesta a incrementar su oferta si la demanda social lo requiere, lo que preveemos pueda ocurrir con la implantación generalizada de los bachilleratos LOGSE, dad la nueva dimensión que el estudio de los idiomas extranjeros adquiere. Resulta evidente por tanto que a priori no podemos concretar los centros educativos que impartirian la enseñanza de este idioma extranjero, ya que sólo a la vista de la tendencia de la demanda podria configurarse esta Red de Centros." 